\title{
Look who's walking: Social and environmental correlates of children's walking in London
}

Rebecca Steinbach'*, Judith Green', Phil Edwards 2

'Faculty of Public Health \& Policy, London School of Hygiene \& Tropical Medicine, I5-I7 Tavistock Place, London WCIH 9SH, United Kingdom.

2 Faculty of Epidemiology \& Population Health, London School of Hygiene \& Tropical Medicine, Keppel St, London WCIE 7HT, United Kingdom.

* Corresponding Author

Rebecca Steinbach

Faculty of Public Health and Policy, London School of Hygiene \& Tropical Medicine, I5-17 Tavistock Place, London WCIH 9SH, United Kingdom.

Telephone: $+44(0) 2079272445$

Fax: +44 (0)207927 270I

Correspondence to: Rebecca.Steinbach@LSHTM.ac.uk 


\section{ABSTRACT}

A substantial literature examines the social and environmental correlates of walking to school but less addresses walking outside the school commute. Using travel diary data from London, we examined social and environmental correlates of walking: to school; outside the school commute during term time; and during the summer and weekends. Living in a household without a car was associated with all journey types; 'Asian' ethnicity was negatively associated with walking for non-school travel; environmental factors were associated with non-school journeys, but not the school commute. Interventions aiming to increase children's active travel need to take account of the range of journeys they make.

Keywords: Children, active travel, walking, environment, social differences 


\section{INTRODUCTION}

There is a growing interest in active travel in public health. Encouraging walking and cycling has been suggested as one way to increase children's physical activity, and thus help tackle the increasing prevalence of overweight and obesity confronting many high income countries (Tudor-Locke et al., 200I). Although there is debate around how much activity is necessary to promote health at an individual level (Bauman, 2004; Saris et al., 2003; Wen et al., 20II), at the population level, incremental changes that decrease sedentary time and increase activity are likely to shift population risk. Efforts have therefore been directed at changing the social and environmental conditions leading to 'energy imbalance', specifically modifying environments such that they encourage physical activity and discourage excessive food intake (French et al., 200I; Roberts and Edwards, 2010). To this end, a large literature is emerging on which environments facilitate or hinder active transport.

\section{The school commute}

As almost all children make a journey to school each day, this represents a key opportunity to engage in active transport and potentially an important contribution to children's levels of physical activity (Roth et al., 20II). Walking to school in the UK is continuing to decline. In 1985, an estimated $67 \%$ of $5-10$ year olds and $52 \%$ of $11-16$ year olds walked to school (Department for Transport, 200I). By 2008, the percentages had decreased to $48 \%$ and $40 \%$ respectively (Department for Transport, 2009). A number of interventions in the UK have focused on reversing this decline. Programmes have included "Walk to School" campaigns (http://www.walktoschool.org.uk/), walking school buses (Mackett et al., 2005) and school travel coordinators (Rowland et al., 2003). However, there have been relatively few evaluations of interventions aimed at children (Ogilvie et al., 2007) and in the absence of evidence on effectiveness a growing literature on the predictors of children's active commuting to school has emerged to help inform policy interventions.

Much of this literature utilises a social ecological framework, which proposes that human behaviour (in this case the decision to walk to school) is influenced both by individual social characteristics and characteristics of the physical and social environment (Stokols, 1996). More complex models such as 
McMillan's conceptual framework (McMillan, 2005) and the Ecological and Cognitive Active Commuting (ECAC) framework build on social ecological models to suggest some of the ways that social and environmental characteristics may interact with each other to produce transport behaviour (Sirard and Slater, 2008). These types of models are designed to be dynamic and therefore continually modified as research illuminates a greater understanding of the mechanisms.

To date, however, reviews of the empirical evidence on relationships between social and environmental factors and active commuting to school have suggested that the findings are difficult to generalise, given the differences between studies on which factors are associated (Davison et al., 2008; Giles-Corti et al., 2009; Jacobsen et al., 2009; Sirard and Slater, 2008). Although, for instance, social characteristics such as age, gender, income and ethnicity (Larsen et al., 2009; McDonald, 2007; McDonald, 2008) have been identified as related to walking to school, associations are not universally found. For instance some international evidence (Ewing et al., 2004; McDonald, 2008; McMillan, 2007) and one UK national-level study (Brophy et al., 20II) have found associations between higher household income and less walking to school. In Norfolk, however, researchers found that children from less deprived areas were more likely to walk to school than children from more deprived areas (Panter et al., 2010). Other international evidence has found no significant associations between household income and walking to school (McMillan et al., 2006). In terms of ethnicity, American studies have suggested that Hispanic children in California (Braza et al., 2004) and African American children in North Carolina (Evenson et al., 2003; McDonald, 2007) and Georgia (US Department of Health and Human Services, 2000) are more likely to walk to school than their white counterparts. A US national study however, found that ethnic differences in travel patterns disappeared when other factors were controlled for (McDonald 2008). The literature on environmental predictors of walking is also difficult to summarise. Although evidence suggests that land use, traffic volumes, road density and street connectivity are all associated with children's use of active transport modes, the salience of any particular environmental characteristic appears to depend on local context (Giles-Corti et al., 2010; Panter et al., 2010; Timperio et al., 2006). One limitation of the empirical literature is that environmental factors are inconsistently defined across studies, and aggregated at varying 
geographical levels (Giles-Corti et al., 2009; Mitra and Buliung, 20II). Additionally, there are likely to be a number of cultural and infrastructural factors that modify relationships, but which are difficult to build into models. The social meaning of walking (as a mode of transport) is, for instance, likely to be locally constituted (Bostock, 200I; Brunton et al., 2006), suggesting that different social factors are likely to help shape transport decisions in different contexts. Second, alternative candidate modes of transport may differ by location if, for instance, some urban areas have relatively good bus provision compared to others. Socio-ecological models, while valuable, are likely to be very context specific.

\section{Non-school travel}

In addition to the school journey, most children also undertake a wide range of other journeys, to activities such as friends' houses, shops, parks, places of worship and clubs. In the UK, the Department for Transport does not publish detailed information on non-school travel, although nonschool journeys made up more than $70 \%$ of all journeys made by children under 17 in 2008 (Department for Transport, 2009). Despite potentially representing a considerable proportion of children's transport time, much less of the empirical and theoretical work on children's walking has focused on non-school travel. This type of active transport may represent a missed opportunity for public health advocates, as walking to non-school activities also provides opportunities for physical exercise. Theoretically, the factors that influence whether children walk to school may be different than those that influence walking during other times. First, the social meaning of walking may differ on school journeys compared to non-school journeys leading to differing associations between social factors and school compared to non-school walking. Second, school journeys are by and large mandatory, with parents responsible for their children's school attendance. Children may therefore have more transport options (for instance, an organised car pool) on school journeys compared to non-school journeys. Finally, school journeys, particularly on the way to school, tend to take place during peak travelling hours when issues such as traffic congestion or public transport overcrowding are more likely to influence transport decisions compared to journeys made at other times. 
The limited international literature on children's non-school travel suggests associations between transport mode and parental attitudes (Hjorthol and Fyhri, 2009; Johansson, 2006; Timperio et al., 2004), vehicle density (Lin and Yu, 20I I), urban area (Sjolie and Thuen, 2002) and perceptions of the local environment (Carver et al., 2005; Timperio et al., 2004), but evidence on the social and environmental correlates of walking outside the school commute is sparse. Within the UK, a small study from Birmingham found perceptions of high traffic volumes and unsafe streets were associated with higher levels of walking to leisure activities, while belonging to a minority ethnic group was negatively associated with number of non-school walking trips (Alton et al., 2007). To inform strategies to increase children's activity across the range of journeys they make, more research is needed to add to the evidence base on non-school travel.

This study aims to contribute to the limited evidence base on non-school active travel, taking London, where there are relatively good data, as a case study. We examine the social and environmental characteristics associated with walking to non-school destinations and compare these to the factors that influence walking on the school commute.

\section{METHODS}

\section{Data sources}

We obtained data on travel by children aged 5 to 171 years for the period 2006 to 2008 from the London Travel Demand Survey (LTDS), an annual survey of travel patterns in Greater London. The LTDS is a rolling survey that randomly selects a total of 8,000 households in London during the year using the UK postcode address file as a sampling frame. The sample design is stratified by London borough to provide 250 households in each of 32 boroughs (excluding City of London). In a face to face interview with a trained interviewer, every member of selected households aged over 5 years is asked to complete a one-day travel diary that recorded the starts, interchanges and ends of every trip on the travel day. The travel days cover both weekdays and weekends. Journey times are

\footnotetext{
${ }^{1}$ The minimum legal driving age in the UK is 17.
} 
collected and 'crow fly' journey distances are estimated using the start-point and end-point of each interchange.

\section{Walking time and distance}

Because the LTDS collects data on each interchange of a journey we were able to calculate the total time spent walking and the distance walked, even if walking was not the primary mode of travel for a particular journey.

\section{Social variables}

The LTDS collects a number of social and household level characteristics including information on age, gender, ethnicity, household income, access to vehicles and household size. Respondents selfselect their ethnicity from UK Census 200 I categories. For analyses, we grouped ethnicity into three main categories: 'White' (White-British, White-Irish, Other White), 'Black' (Black or Black BritishCaribbean, Black or Black British-African, Black or Black British-Other Black background, MixedWhite and Black African, Mixed-White and Black African), and 'Asian' (Asian or Asian British- Indian, Asian or Asian British- Pakistani, Asian or Asian British-Bangladeshi, Asian or Asian British-other Asian background, Mixed-White and Asian). Other ethnic groups (4\%) and those who declined to select an ethnicity ( $1 \%)$ were not considered in the analyses. Household income is available in banded income groups only which we analysed as terciles (0- $£|4,999, £| 5,000-£ 49,999$, and $£ 50,000+)$.

\section{Environmental variables}

We assigned each child to a neighbourhood (Census Lower Super Output Area, LSOA) using the centroid of the postcode where they live. LSOAs are small geographic areas corresponding to an average of I,500 residents. Data on the social environment was obtained using the 2004 Index of Multiple Deprivation (IMD) which brings together 36 indicators across seven different domains of deprivation into an overall score (Noble et al., 2007). LSOAs were ranked according to IMD and divided into quintiles (I least deprived to 5 most deprived). Based on evidence from the literature, we selected from available data on the physical environment those variables with known associations with walking among children (Frank et al., 2007; Giles-Corti et al., 2009; Giles-Corti et al., 2010; 
Jacobsen et al., 2009; McMillan, 2007; Panter et al., 2010; Schlossberg et al., 2006; Timperio et al., 2006). These included density of $A$ roads, density of minor roads and number of junctions (as measures of street connectivity), the proportion of postcodes in an LSOA characterised as business (as a measure of residential density/land use), and average speed and volume of traffic.

\section{Geographical Information System (GIS) analysis}

To create variables describing the road environment in an LSOA, road network information from the Integrated Transport Network (ITN) supplied by Ordnance Survey was overlaid with LSOA boundaries provided by the census in ArcView GIS. Data on average traffic speeds and volumes came from the London Greenhouse Gas Inventory (LEGGI). LEGGI data, typically used to measure greenhouse gas emissions, includes measurements of volume of traffic by vehicle type and traffic speeds. To calculate LSOA summaries of average speeds and volumes the LEGGI road network was overlaid with LSOA boundaries.

\section{Statistical analyses}

We examined correlations between each environmental variable to assess the potential for multicollinearity. Variables were included in the analysis if correlation coefficients were less than 0.6 . Survey weights (adjusted for non-response and scaled to mid-2007 population projections) were used to ensure that the sample was representative of the London population. All analyses allowed for the stratification of the sample by London borough.

We fitted three logistic regression models to explore the relationship between social and environmental characteristics and walking for transport:

(I) doing some walking on the journey to school

(2) doing some walking to other destinations during term time

(3) doing some walking during summer holidays and weekends.

All social and environmental characteristics were included in models I-3 simultaneously. To minimize the influence that potential under-reporting of very short trips might have on the results, children 
were categorized as 'doing some walking' if they walked more than 100 metres. Much research to predict walking behaviour has considered a child to be a 'walker' only if the child walks the entire way from start to the end of the journey (McDonald, 2008; Robertson-Wilson et al., 2008). However, travel using public transport modes may offer opportunities for substantial amounts of walking, particularly in urban areas (Julien and Carre, 2002). In London, where children have had access to free bus travel since 2005 , walking en route to, or from, a bus stop may constitute a large proportion of the children's walking. Therefore, analyses consider all walking done by children, whether as part of a public transport trip or all the way to their destination. Sensitivity analyses were conducted that consider walking all the way to school as the outcome variable.

Linear regression models were used to explore factors related to the distance walked and total time spent walking across all journeys among children who did some walking. A natural logarithm transformation of distance and time variables was used to allow for non-normality of the distributions. In the descriptive analyses age was categorised into primary school aged (5-II) and secondary school aged (12-17) children. In the multivariable analyses we included age as an integer variable. Tables report analyses based on walking distance. Results on walking times are available in a web appendix. 


\section{RESULTS}

The LTDS provided data on 36,473 interchanges within 18,537 trips among 8,082 children aged 5-17 years in London from 2006-2008. The sample included 4,5I3 children during term time and 3,569 during the summer and weekends. The survey suggests that $68 \%$ of children do some walking on the way to school, $24 \%$ do some walking to other destinations during term time and $48 \%$ do some walking during the summer and weekends. On average children in London walk for 16.8 minutes (95\% Cl 16.2-17.4) and a distance of $0.82 \mathrm{~km}(0.78-0.85)$ to school per day (including those who do not walk at all). Children walk a daily average of 5.4 minutes (4.8-5.9) and a distance of $0.28 \mathrm{~km}$ $(0.26-0.30)$ to other activities during term time. During the summer and weekends children walk an average of 12.8 minutes (II.9- I2.6) and a distance of $0.66 \mathrm{~km}(0.6 \mathrm{I}-0.7 \mathrm{I})$ per day.

Older children (aged 12-17) appear to walk longer and further distances than younger children (aged 5-II) across all journey types (Table I for walking distances; Web-appendix for walking times). There was no evidence of gender differences in overall minutes or kilometres walked by children. 'Black' children appear to walk longer and further distances to school compared to children from other ethnic groups, but they appear to walk less than 'White' children outside the school commute and during summer/weekends (though differences are not significant). 'Asian' children appear to walk less than 'Black' or 'White' children outside of travel to school during the week and during summer/weekends. Children from households earning less than $£ 15,000$ annually and children from households without access to a vehicle walk further and longer than their more affluent counterparts. Children living in areas with relatively high traffic volumes spend more time walking outside the school commute and during summer/weekends, but spend similar amounts of time walking to school as children from areas with relatively lower traffic volumes.

Table 2 presents odds ratios with $95 \%$ confidence intervals and $p$ values for the associations between social and environmental factors and walking to school, walking during term time for other purposes, and walking during the summer and weekends. F-adjusted mean residual goodness-of-fit tests (Archer et al., 2007) suggest that all models fit the data reasonably well $(p=0.796$ for walking to school and 
$\mathrm{p}=0.86 \mathrm{I}$ for both walking during term time for other purposes and during summer and weekends) Children living in households without access to a vehicle were considerably more likely to walk to school (OR $2.3395 \% \mathrm{Cl}$ I.86-2.92), outside the school commute during term time (I.38, I.I0-I.73), and during the summer/weekends (I.82, I.47-2.26) than children living in households with vehicle access. 'Black' and 'Asian' children were marginally more likely to do some walking on the school journey compared to 'White' children, but 'Asian' children in particular were less likely to walk outside the school commute during term time. No characteristics of the social or physical environment significantly predicted children's walking to school. However, several environmental characteristics were associated with walking outside the school commute and during the summer and weekends. Living in an area with a larger proportion of postcodes characterized as 'business' was associated with an increased likelihood of walking outside the school commute and during summer/weekends, whereas a higher number of road junctions was associated with a decreased likelihood of walking. Living in an area with higher traffic volumes and lower speeds was associated with an increased likelihood of walking during the summer/weekends.

Among children who did do some walking, age and living in a household without access to a vehicle were positively associated with walking distances (Table 3) and times (Web appendix). Being 'Black' or 'Asian' was negatively associated with walking times and distances. While we found no gender differences in the total amount of time spent walking, being female was marginally associated with greater walking time among children who did some walking (Web appendix). Traffic speeds were negatively associated with walking distance and marginally negatively associated with walking times. Traffic volumes were marginally positively associated with walking distances and times. Density of $A$ roads and density of minor roads were marginally negatively associated with walking distances.

A sensitivity analysis examining the social and environmental correlates of walking all the way to school suggested that children living in a household without access to vehicles, children living in households earning between $€ \mid 5,000-50,000$ and 'Asian' children were more likely to walk all the way to school compared to their counterparts, while older children and 'Black' children were less 
likely to walk all the way to school compared to others (Web appendix). Traffic volumes were negatively associated and traffic speeds were positively associated with walking all the way to school among children.

\section{DISCUSSION}

\section{Principal findings}

We have used travel diary data from the LTDS to examine the social and environmental correlates of walking for transport among children in London. We found that living in a household without access to vehicles was strongly associated with walking on the school commute, and associated (though less strongly) with non-school travel. Belonging to a 'Black or 'Asian' minority ethnic group was marginally associated with walking on the way to school. This study hypothesized that characteristics that influence walking to school might differ from those that influence walking behaviour outside the school commute. While we found no association between the physical environment and doing some walking on the school journey, we did find some evidence that high traffic volumes, low traffic speeds, and a high proportion of businesses in an area were associated with walking outside the school commute or during weekends/summer. We also found that unlike the school commute, belonging to an 'Asian' minority ethnic group was associated with less walking for non-school journeys.

\section{Strengths and weaknesses}

Using travel diaries to assess walking behaviour has some notable limitations including underreporting of short walking trips. However, other methods such as accelerometers and GPS devices have their own difficulties (Mackett et al., 2007) and travel diaries have been successfully used to examine children's walking in international contexts (Frank et al., 2007; McDonald, 2008). Travel diary data also has a number of benefits. The LTDS allowed for analyses of all walking behaviour (including any walking undertaken as part of a public transport journey) and integration of multiple 
data sources on the physical and social environment. The use of straight line 'crow fly' distance to measure kilometres walked may be problematic as this method tends to underestimate distances walked (Stigell and Schantz, 20II). The actual distance travelled can be substantially longer than the 'crow fly' distance in suburban areas, whereas the difference would be less in inner-city neighbourhoods. In other words, measurement error will not be equal or random across space.

We investigated this potential bias by repeating our analyses of the social and environmental associations of distance walked among children who do some walking (Table 3) using minutes walked as an alternative outcome measure (Web-appendix). As reported above, we found that the characteristics associated with distance walked were similar to the characteristics associated with minutes walked. We did not investigate the potential influence on our results of distances to schools, and other destinations (e.g. to bus or train stations), Distance is an important predictor of mode choice (McMillan, 2007; Nelson et al., 2008; Sjolie and Thuen, 2002), and may confound some of the observed relationships between social and environmental characteristics and walking all the way to school (presented in the web-appendix). For example, the negative association between age and walking all the way to school may be partly explained by older children attending schools further from home.

Similar to other studies (Panter et al., 2010), this study used the Index of Multiple Deprivation as a measure of the social environment, which may be an imperfect proxy for the complex ways in which social processes are spatially embedded. We found no association between our measure of the social environment and walking during the school commute or during non-school travel. Other studies have found associations between the social environment and active travel using more specific measures including neighbourhood cohesion (McDonald, 2007), perceived criminal danger (Kerr et al., 2006), and abduction fears (Timperio et al., 2006).

This study was only able to access 'objective' measures of the road environment, measured using GIS systems. Research in urban planning has identified conceptual links between perceived characteristics of the built environment and objective measures (McMillan, 2005; Mitra et al., 2010). Empirically, 
there is some evidence that perceived characteristics of the environment are more salient in predicting walking behaviour compared to objectively measured environmental characteristics (McGinn et al., 2007). Unfortunately these types of data on the perceived characteristics of the social and physical environment were not available for London.

Finally, quantitative analyses of the social and environmental correlates of walking behaviour can't tell us anything about the experience of walking or draw out how the meaning of walking may differ by social or environmental contexts. Given the difficulties in generalising the social and environmental correlates of walking, both across studies from different locations and (in this study) across different journeys, more qualitative research may be needed to illuminate these meanings in context.

\section{$\underline{\text { Interpretation and mechanisms }}$}

Our findings on the social correlates or walking to school reflect those in other studies: living in a household without access to a vehicle (Frank et al., 2007) and belonging to a minority ethnic group (McDonald, 2007) were positively associated with walking to school. However unlike other studies (Giles-Corti et al., 2010; Timperio et al., 2006), we found little evidence that the social or physical environment was associated with walking to school. This may reflect the way in which we defined walking (i.e defining a child as a 'walker' if they walked during any part of their school journey). In an environment like London, where the level of car ownership is relatively low compared the rest of the nation and public transport provision is relatively good (Transport for London, 2009), the physical environment may be less relevant in predicting walking to school than in other settings.

Our findings on the social correlates of walking outside the school commute are similar to the only other UK study to address non-school active travel (Alton et al., 2007); living in a household without access to a vehicle was positively associated with non-school active travel; while belonging to an 'Asian' minority group was negatively associated. Unlike travel to school, we found a number of characteristics of the physical environment were associated with walking outside school commutes. This may indicate, as others have suggested (Ewing et al., 2004), that the walking environment may be 
relatively more important on discretionary trips compared to the school commute. Speculatively, areas with higher volumes of traffic and, crucially, lower speeds (which were associated with an increased likelihood of walking), may be perceived as safer to walk around than those with higher speeds. There is some evidence that the influence of the environment on walking differs by walking purpose among adults where research has found that environmental attributes associated with walking for exercise differed from those associated with walking for transport (Owen et al., 2004).

Our conflicting findings on ethnicity and active travel highlight the importance of considering walking on the school commute and non-school transport separately. While this research did not set out to unpick the complex ways that ethnicity may be related to transport decisions it is important to recognise the potential mechanisms that may link ethnicity to walking behaviour. A number of factors related to both ethnicity as identity and ethnicity as structure may be related to the amount of walking done by children (Steinbach et al., 2010).

This study found that 'Black' children appear to be more likely to do some walking on the way to school compared to 'White' children but are less likely to walk all the way to school. Further, among those who do walk for any purpose, distances tend to be shorter than those among 'White' children. Structural links between ethnicity and household socio-economic disadvantage suggest that 'Black' children may be less likely to live in a household with access to a vehicle (Department for Transport, 2009) and so they may be more likely to do some walking on the school journey.

However, in London 'Black' children tend to live further away from school (Department for Education, 2010) which may make walking all the way to school impractical. Evidence suggests that walking all the way to school is only considered feasible for relatively short distances of roughly $\mathrm{I}-\mathrm{I} .5$ kilometres (McDonald, 2007; Nelson et al., 2008). Walks to bus stops are likely to be relatively shorter. Structural associations between ethnicity and area disadvantage suggest that Black children also live in more dense urban areas, particularly in London where the proportion of the population that is 'Black' is twice as high in inner London compared to outer London (ONS, 20I0). In denser 
urban areas travels outside the school commute (ie. to see friends/to shops/etc) may cover less distance.

We did not find strong evidence to suggest that 'Asian' children were less likely to walk to school compared to 'White' children. However we did find that 'Asian' children were considerably less likely to do any walking outside the school commute or during the summer/weekends. Other research has suggested that 'Asian' children have lower physical activity levels overall compared to 'White' children (Brodersen et al., 2007; Owen et al., 2009). Again, these findings may be related to both ethnicity as identity and ethnicity as structure. Qualitative evidence suggests that structural associations with experiences of racism may deter some 'Asian' children from non-school activities (Morrow, 2000; Steinbach et al., 2007). Ethnic identity factors, such as cultural preferences due to religious beliefs and social norms, may affect the amount of spare time enjoyed by children and therefore the number of leisure activities in which they are able to participate (Phoenix and Husain, 2007).

Finally, the cultural significance of walking for transport may very well differ by ethnicity, leading to ethnic differences in active travel. Social identities shape transport decisions (Steinbach et al., 20I I), as transport mode choice depends not only on the attributes of a particular mode but also the meanings of each mode in local context. There is relatively little work examining the cultural resonances of transport modes in different ethnic groups, and more research is needed to examine the meaning of walking and explore how it might differ among social groups.

\section{Implications}

This study suggests that the factors that influence walking to school can differ from factors that influence walking for other journeys. While currently an area that tends to be overlooked by policy makers, increasing children's non-school active travel has the potential to offer public health benefits but may require different public health strategies. Public health strategies are generally designed to increase the amount of physical activity within the population, rather than to necessarily achieve clinically important changes in individual behaviour, such as getting children to achieve a threshold of 
activity. This study therefore included all walking, rather than just journeys where walking was the main mode, as this is important at a population level. Given that few children walked the whole distance to school, but the majority did some walking, interventions that increase the number of children doing some walking, and increase the amount of walking they do, may be as important as those aiming to change the main mode of transport. Here, interventions to improve access to public transport may be useful for increasing the general level of activity among young people. Our data suggest that even in London, with a relatively good public transport infrastructure and low car ownership compared to the rest of the UK (Transport for London, 2009), lacking access to a car was associated with walking for all types of journey: there may be more scope for reducing children's car use, and thus increasing their physical activity rates as they move to public transport options. Given the range of findings from the literature on the social and environmental correlates of walking, and the suggestion that local social and cultural contexts are important determinants of walking, it is perhaps not surprising that our study identified differences in the correlates of school and nonschool walking. The meaning of choosing walking compared with other candidate modes is likely to vary depending on whether the journey has to be done (eg for school) and what the alternatives are. For discretionary non-school journeys, the alternative may be forgoing the journey. Disincentives to active transport are therefore potentially also disincentives for social participation, and more attention must be paid to factors that restrict children's mobility. For non-school journeys, our findings suggest that the environment is a more important influence on walking, and that more efforts to reduce traffic speeds, in particular, are likely to encourage active transport.

This study, like much of the current evidence base, used a cross sectional design to examine walking. Further research, in particular using more sophisticated and qualitative methods is needed to examine the social meaning of walking in particular environments to help deepen our understanding. 


\section{Highlights}

- Social and environmental correlates of children's non-school and school commute walking differ in one large urban setting

- The social meaning of walking may be as significant as the environment in predicting travel behaviour

- Increasing children's non-school active travel has the potential to offer public health benefits but may require different public health strategies

\section{Acknowledgements}

We are grateful to two anonymous referees for very helpful comments on earlier versions of this paper. London Travel Demand Survey data were provided by Dale Campbell at Transport for London. The road network used was OS ITN layer supplied by Transport for London under licence and is copyright Ordnance Survey. Census boundary data were supplied with the support of ESRC and are Crown copyright. 


\section{REFERENCES}

Alton, D., Adab, P., Roberts, L., Barrett, T., 2007. Relationship between walking levels and perceptions of the local neighbourhood environment. Archives of Disease in Childhood 92, 29-33.

Archer, K.J., Lemeshow, S., Hosmer, D.W., 2007. Goodness-of-fit tests for logistic regression models when data are collected using a complex sampling design.

Computational Statistics \& Data Analysis 5 I, 4450-4464.

Bauman, A., 2004. Updating the evidence that physical activity is good for health: an epidemiological review 2000-2003. Journal of Science and Medicine in Sport 7, 6- 19.

Bostock, L., 200 I. Pathways of disadvantage? Walking as a mode of transport among low-income mothers. Health \& Social Care in the Community 9, I I-I8.

Braza, M., Shoemaker, W., Seeley, A., 2004. Neighborhood design and rates of walking and biking to elementary school in 34 California communities. American Journal of Health Promotion 19, 128-136.

Brodersen, N.H., Steptoe, A., Boniface, D.R., Wardle, J., 2007. Trends in physical activity and sedentary behaviour in adolescence: ethnic and socioeconomic differences. British Journal of Sports Medicine 4 I:, I40-I44.

Brophy, S., Cooksey, R., Lyons, R., Thomas, N., Rodgers, S., Gravenor, M., 201 I. Parental factors associated with walking to school and participation in organised activities at age 5: Analysis of the Millennium Cohort Study. BMC Public Health II, I4.

Brunton, G., Oliver, S., Oliver, K., Lorenc, T., 2006. A synthesis of research addressing children's, young people's and parents' views of walking and cycling for transport. The Evidence for Policy and Practice Information and Coordinating Centre (EPPI - Centre) Institute of Education, University of London, London.

Carver, A., Salmon, J., Campbell, K., Baur, L., Garnett, S., Crawford, D., 2005. How do perceptions of local neighbourhood relate to adolescent's walking and cycling?

American Journal of Health Promotion 20, 139 - 147.

Davison, K.K., Werder, J.L., Lawson, C.T., 2008. Children's active commuting to school: current knowledge and future directions. Preventing Chronic Disease 5, Al 00.

Department for Education, 20 I0. Statistics of Education: school destinations of secondary school pupils resident in London boroughs, 2010 , Statistical Bulletin. Department for Education.

Department for Transport, 200 I. Transport Statistics Bulletin. National Travel Survey 1999/200 I update. Office for National Statistics.

Department for Transport, 2009. Transport Statistics Bulletin. National Travel Survey 2008. Office for National Statistics.

Evenson, K.R., Huston, S.L., McMillen, B.J., Bors, P., Ward, D.S., 2003. Statewide Prevalence and Correlates of Walking and Bicycling to School. Archives of Pediatrics \& Adolescent Medicine I57, 887-892. 
Ewing, R., Schroeer, W., Greene, W., 2004. School location and student travel: analysis of factors affecting mode choice. Transportation Research Record: Journal of the Transportation Research Board 1895, 55-63.

Frank, L., Kerr, J., Chapman, J., Sallis, J., 2007. Urban form relationships with walk trip frequency and distance among youth. American Journal of Health Promotion 21, 305 3 II.

French, S., Story, M., Jeffery, R., 200 I. Environmental influences on eating and physical activity. Annu Rev Public Health 22, 309-335.

Giles-Corti, B., Kelty, S., Zubrick, S., Villanueva, K., 2009. Encouraging Walking for Transport and Physical Activity in Children and Adolescents: How Important is the Built Environment? Sports Medicine 39, 995-1009.

Giles-Corti, B., Wood, G., Pikora, T., Learnihan, V., Bulsara, M., Van Niel, K., Timperio, A., McCormack, G., Villanueva, K., 20I0. School site and the potential to walk to school: The impact of street connectivity and traffic exposure in school neighborhoods. Health \& Place In Press, Corrected Proof.

Hjorthol, R., Fyhri, A., 2009. Do organized leisure activities for children encourage caruse? Transportation Research Part A: Policy and Practice 43, 209-2I 8.

Jacobsen, P.L., Racioppi, F., Rutter, H., 2009. Who owns the roads? How motorised traffic discourages walking and bicycling. Injury Prevention I5, 369-373.

Johansson, M., 2006. Environment and parental factors as determinants of mode for children's leisure travel. Journal of Environmental Psychology 26, I56-169.

Julien, A., Carre, J., 2002. Risk exposure during pedestrian journeys. Recherche Transports Securite 76, I73-I89.

Kerr, J., Rosenberg, D., Sallis, J., Saelens, B., Frank, L., Conway, T., 2006. Active commuting to school: Associations with environment and parental concerns. Medicine and Science in Sports and Exercise 38, 787 - 794.

Larsen, K., Gilliland, J., Hess, P., Tucker, P., Irwin, J., He, M., 2009. The influence of the physical environment and sociodemographic characteristics on children's mode of travel to and from school. American Journal of Public Health 99, 520-526.

Lin, J., Yu, T., 20I I. Built environment effects on leisure travel for children: trip generation and travel mode. Transport Policy 18.

Mackett, R., Banister, D., Batty, M., Einon, D., Brown, B., Gong, Y., Kitazawa, K., Marshall, S., Paskins, J., 2007. Final report on 'Children's Activities, Perceptions and Behaviour in the Local Environment (CAPABLE)'. Univeristy College London.

Mackett, R., Lucas, L., Paskins, J., Turbin, J., 2005. Walking buses in Hertfordshire: Impacts and lessons. Centre for Transport Studies, University Colledge London, London.

McDonald, N., 2007. Travel and the social environment: Evidence from Alameda County, California. Transportation Research Part D: Transport and Environment I 2, 53 - 63. 
McDonald, N.C., 2008. Critical Factors for Active Transportation to School Among Low-Income and Minority Students: Evidence from the 200 I National Household Travel Survey. American Journal of Preventive Medicine 34, 34 I-344.

McGinn, A.P., Evenson, K.R., Herring, A.H., Huston, S.L., 2007. The relationship between leisure, walking, and transportation activity with the natural environment. Health \& Place 13, 588-602.

McMillan, T., 2005. Urban form and a child's trip to school: The current literature and framework for future research. Journal of Planning Literature 19, 440 - 456.

McMillan, T., 2007. The relative influence of urban form on a child's travel mode to school. Transportation Research Part A: Policy and Practice 4I, 69 - 79.

McMillan, T., Day, K., Boarnet, M., Alfonzo, M., Anderson, C., 2006. Johnny walks to school-- does Jane? Children, Youth and Environments 16.

Mitra, R., Buliung, R., Roorda, M., 2010. Built environment and school travel mode choice in Toronto, Canada. Transportation Research Record 2156, I50-159.

Mitra, R., Buliung, R.N., 20 I I. Built environment correlates of active school transportation: neighborhood and the modifiable areal unit problem. Journal of Transport Geography.

Morrow, V.M., 2000. 'Dirty looks' and 'trampy places' in young people's accounts of community and neighbourhood: implications for health inequalities. Critical Public Health 10, $141-152$.

Nelson, N., Foley, E., O'Gorman, D., Moyna, N., Woods, C., 2008. Active commuting to school: How far is too far? International Journal of Behavioral Nutrition and Physical Activity 5, I.

Noble, M., McLennan, D., Wilkinson, K., Whitworth, A., Barnes, H., Dibben, C., 2007. The English Indices of Deprivation.

Ogilvie, D., Foster, C.E., Rothnie, H., Cavill, N., Hamilton, V., Fitzsimons, C.F., Mutrie, N., 2007. Interventions to promote walking: systematic review. BMJ 334, I 204.

ONS, 20 I0. Population estimates by ethnic group, National Statistics Online.

Owen, C.G., Nightingale, C.M., Rudnicka, A.R., Cook, D.G., Ekelund, U., Whincup, P.H., 2009. Ethnic and gender differences in physical activity levels among 9-10-year-old children of white European, South Asian and African-Caribbean origin: the Child Heart Health Study in England (CHASE Study). International Journal of Epidemiology 38, 1082-1093.

Owen, N., Humpel, N., Leslie, E., Bauman, A., Sallis, J.F., 2004. Understanding environmental influences on walking: Review and research agenda. American Journal of Preventive Medicine 27, 67-76.

Panter, J.R., Jones, A.P., Van Sluijs, E.M.F., Griffin, S.J., 20I O. Neighborhood, Route, and School Environments and Children's Active Commuting. American Journal of Preventive Medicine 38, 268-278.

Phoenix, A., Husain, F., 2007. Parenting and ethnicity. Joseph Rowntree Foundation. 
Roberts, I., Edwards, P., 20 I0. The Energy Glut: The Politics of Fatness in an Overheating World. Zed Books Ltd, London.

Robertson-Wilson, J.E., Leatherdale, S.T., Wong, S.L., 2008. Social-Ecological Correlates of Active Commuting to School Among High School Students. Journal of Adolescent Health 42, 486-495.

Roth, M.A., Millett, C.J., Mindell, J.S., $20 \mathrm{I}$ I. The contribution of active travel (walking and cycling) in children to overall physical activity levels: a national cross sectional study. Preventive Medicine.

Rowland, D., DiGuiseppi, C., Gross, M., Afolabi, E., Roberts, I., 2003. Randomised controlled trial of site specific advice on school travel patterns. Archives of Disease in Childhood 88, 8-I I.

Saris, W., Blair, S., van Baak, M., Eaton, S., Davies, P., Di Pietro, L., Fogelholm, M., Rissanen, A., Schoeller, D., Swinburn, B., Tremblay, A., Westerterp, K., Wyatt, H., 2003. How much physical activity is enough to prevent unhealthy weight gain? Outcome of the IASO Ist Stock Conference and consensus statement. Obesity Reviews 4, I 0 III4.

Schlossberg, M., Greene, J., Phillips, P., Johnson, B., Parker, B., 2006. School trips: Effects of urban form and distance on travel mode. Journal of American Planning Association 72, 337 - 346.

Sirard, J.R., Slater, M.E., 2008. Walking and Bicycling to School: A Review. American Journal of Lifestyle Medicine 2, 372-396.

Sjolie, A.N., Thuen, F., 2002. School journeys and leisure activities in rural and urban adolescents in Norway. Health Promotion International I 7, 2 I-30.

Steinbach, R., Edwards, P., Green, J., Grundy, C., 2007. Road Safety of London's Black and Asian Minority Ethnic Groups: A report to the London Road Safety Unit London: LSHTM.

Steinbach, R., Green, J., Datta, J., Edwards, P., 20I I. Cycling and the city: A case study of how gendered, ethnic and class identities can shape healthy transport choices. Social Science \& Medicine 72, I I 23- I I 30.

Steinbach, R., Green, J., Edwards, P., Grundy, C., 2010 . 'Race' or place? Explaining ethnic variations in childhood pedestrian injury rates in London. Health and Place 16, 34-42.

Stigell, E., Schantz, P., $20 \mathrm{I}$ I. Methods for determining route distances in active commuting - Their validity and reproducibility. Journal of Transport Geography 19, 563574.

Stokols, D., 1996. Translating social ecological theory into guidelines for community health promotion. American Journal of Health Promotion 10, 282-298.

Timperio, A., Ball, K., Salmon, J., Roberts, R., Giles-corti, B., Simmons, D., Baur, L., Crawford, D., 2006. Personal, family, social, and environmental correlates of active commuting to school. American Journal of Preventive Medicine 30, 45 - 5 I.

Timperio, A., Crawford, D., Telford, A., Salmon, J., 2004. Perceptions about the local neighbourhood and walking and cycling among children. Preventive Medicine 38, 39 - 47. 
Transport for London, 2009. Travel in London: key trends and developments Transport for London, London.

Tudor-Locke, C., Ainsworth, B., Popkin, B., 200I. Active commuting to school: An overlooked source of childrens' physical activity? Sports Med 3 I, 309 - 3 I 3.

US Department of Health and Human Services, 2000. Healthy People 20 I 0: Objectives for Improving Health. US Public Health Service, Washington, DC.

Wen, C.P., Wai, J.P.M., Tsai, M.K., Yang, Y.C., Cheng, T.Y.D., Lee, M.-C., Chan, H.T., Tsao, C.K., Tsai, S.P., Wu, X., $20 \mathrm{II}$. Minimum amount of physical activity for reduced mortality and extended life expectancy: a prospective cohort study. The Lancet 378, I 244-I 253. 
Table I: Mean distances (kilometres) walked by children by selected social and environmental characteristics

\begin{tabular}{|c|c|c|c|c|c|c|c|}
\hline \multirow[b]{2}{*}{ Demographic } & \multicolumn{3}{|c|}{ Term time weekday travel to school } & \multicolumn{2}{|c|}{$\begin{array}{l}\text { Term time weekday other } \\
\text { travel }\end{array}$} & \multicolumn{2}{|c|}{ Summer and weekend travel } \\
\hline & $\begin{array}{c}\% \text { Do } \\
\text { some } \\
\text { walking }\end{array}$ & $\begin{array}{c}\% \text { Walk } \\
\text { all the } \\
\text { way }\end{array}$ & $\begin{array}{l}\text { Mean distance } \\
\text { walked }(\mathrm{km})\end{array}$ & $\begin{array}{c}\text { Mean distance } \\
\text { walked }(\mathrm{km})\end{array}$ & $\begin{array}{c}\text { sample } \\
\text { size }\end{array}$ & $\begin{array}{c}\text { Mean distance } \\
\text { walked }(\mathrm{km})\end{array}$ & $\begin{array}{l}\text { sample } \\
\text { size }\end{array}$ \\
\hline \multirow{2}{*}{\multicolumn{8}{|c|}{$\begin{array}{l}\text { Social characteristics } \\
\text { Age }\end{array}$}} \\
\hline & & & & & & & \\
\hline $5-11$ & $69 \%$ & $15 \%$ & $0.62(0.58-0.65)$ & $0.20(0.17-0.23)$ & 2486 & $0.54(0.49-0.59)$ & I,948 \\
\hline $12-17$ & $67 \%$ & $31 \%$ & $1.04(0.98-1.10)$ & $0.37(0.33-0.4 I)$ & 2027 & $0.80(0.70-0.87)$ & $|, 62|$ \\
\hline \multicolumn{8}{|l|}{ Gender } \\
\hline Male & $68 \%$ & $23 \%$ & $0.83(0.78-0.87)$ & $0.27(0.23-0.30)$ & 2315 & $0.64(0.58-0.7 I)$ & ।,770 \\
\hline Female & $68 \%$ & $23 \%$ & $0.8 \mathrm{I}(0.76-0.86)$ & $0.30(0.26-0.33)$ & 2198 & $0.68(0.60-0.76)$ & ।,799 \\
\hline \multicolumn{8}{|l|}{ Ethnic group } \\
\hline 'White' & $65 \%$ & $23 \%$ & $0.82(0.77-0.87)$ & $0.31(0.28-0.34)$ & 2560 & $0.70(0.63-0.76)$ & 1,909 \\
\hline 'Black' & $74 \%$ & $22 \%$ & $0.86(0.79-0.93)$ & $0.27(0.22-0.32)$ & 882 & $0.62(0.53-0.70)$ & 721 \\
\hline 'Asian' & $71 \%$ & $26 \%$ & $0.78(0.69-0.87)$ & $0.18(0.13-0.22)$ & 831 & $0.51(0.42-0.60)$ & 716 \\
\hline \multicolumn{8}{|l|}{ Household income } \\
\hline$>€ 50 k$ & $62 \%$ & $19 \%$ & $0.75(0.68-0.8 I)$ & $0.30(0.25-0.35)$ & 1143 & $0.67(0.56-0.77)$ & 880 \\
\hline$£ 15-50$ & $67 \%$ & $24 \%$ & $0.81(0.75-0.86)$ & $0.24(0.21-0.27)$ & 2068 & $0.67(0.59-0.75)$ & ।,677 \\
\hline$<\epsilon \mid 5 k$ & $74 \%$ & $25 \%$ & $0.88(0.82-0.94)$ & $0.32(0.27-0.36)$ & 1302 & $0.65(0.58-0.72)$ & 1,012 \\
\hline \multicolumn{8}{|l|}{ Vehicle access } \\
\hline Access & $63 \%$ & $21 \%$ & $0.75(0.7 I-0.79)$ & $0.25(0.23-0.28)$ & 3371 & $0.59(0.54-0.65)$ & 2,702 \\
\hline No access & $81 \%$ & $29 \%$ & $0.98(0.92-1.04)$ & $0.35(0.30-0.40)$ & 1142 & $0.83(0.73-0.93)$ & 867 \\
\hline \multicolumn{8}{|l|}{$\begin{array}{l}\text { Environmental } \\
\text { characteristics }\end{array}$} \\
\hline \multicolumn{8}{|l|}{ Location } \\
\hline Inner London & $73 \%$ & $26 \%$ & $0.8 \mathrm{I}(0.75-0.87)$ & $0.28(0.25-0.32)$ & 1546 & $0.68(0.60-0.75)$ & I, 178 \\
\hline Outer London & $65 \%$ & $22 \%$ & $0.82(0.78-0.86)$ & $0.28(0.25-0.31)$ & 2967 & $0.65(0.59-0.72)$ & 2,391 \\
\hline $\begin{array}{l}\text { Area Deprivation } \\
\text { (least deprived) Q I }\end{array}$ & $63 \%$ & $20 \%$ & $0.81(0.73-0.89)$ & $0.28(0.22-0.34)$ & 821 & $0.72(0.57-0.87)$ & 736 \\
\hline Q2 & $64 \%$ & $21 \%$ & $0.84(0.75-0.93)$ & $0.31(0.24-0.38)$ & 851 & $0.57(0.49-0.66)$ & 704 \\
\hline Q3 & $68 \%$ & $22 \%$ & $0.88(0.78-0.98)$ & $0.29(0.24-0.34)$ & 927 & $0.73(0.62-0.84)$ & 690 \\
\hline & $69 \%$ & $23 \%$ & $0.78(0.72-0.85)$ & $0.25(0.20-0.29)$ & 936 & $0.64(0.55-0.74)$ & 733 \\
\hline (most deprived) Q5 & $75 \%$ & $30 \%$ & $0.78(0.72-0.84)$ & $0.28(0.23-0.32)$ & 978 & $0.64(0.54-0.73)$ & 706 \\
\hline \multicolumn{8}{|l|}{$\begin{array}{l}\text { Mean traffic } \\
\text { volumes }\end{array}$} \\
\hline (least traffic) TI & $69 \%$ & $24 \%$ & $0.82(0.76-0.88)$ & $0.21(0.18-0.24)$ & 1552 & $0.57(0.48-0.65)$ & 1,205 \\
\hline $\mathrm{T} 2$ & $70 \%$ & $22 \%$ & $0.84(0.78-0.90)$ & $0.30(0.26-0.34)$ & 1565 & $0.70(0.61-0.78)$ & 1,302 \\
\hline (most traffic) T3 & $66 \%$ & $24 \%$ & $0.79(0.72-0.85)$ & $0.33(0.29-0.38)$ & 1396 & $0.72(0.63-0.80)$ & 1,062 \\
\hline \multicolumn{8}{|l|}{ Traffic speeds } \\
\hline$<25 \mathrm{kph}$ & $72 \%$ & $24 \%$ & $0.79(0.72-0.85)$ & $0.28(0.23-0.33)$ & 873 & $0.71(0.62-0.80)$ & 739 \\
\hline $25-35 \mathrm{kph}$ & $68 \%$ & $23 \%$ & $0.84(0.80-0.89)$ & $0.28(0.25-0.31)$ & 2997 & $0.66(0.60-0.73)$ & 2,417 \\
\hline$>35 \mathrm{kph}$ & $65 \%$ & $25 \%$ & $0.74(0.65-0.83)$ & $0.27(0.20-0.34)$ & 643 & $0.56(0.44-0.67)$ & 413 \\
\hline
\end{tabular}


Table 2: Associations between social and environmental characteristics and doing some walking for transport

\begin{tabular}{|c|c|c|c|c|c|c|c|c|c|}
\hline \multirow[b]{2}{*}{ Characteristic } & \multicolumn{3}{|c|}{ Term time weekday travel to school } & \multicolumn{3}{|c|}{ Term time weekday other travel } & \multicolumn{3}{|c|}{ Summer and weekend travel } \\
\hline & OR & $95 \% \mathrm{Cl}$ & $p$-value & OR & $95 \% \mathrm{Cl}$ & $p$-value & OR & $95 \% \mathrm{Cl}$ & $\mathrm{p}$-value \\
\hline \multicolumn{10}{|l|}{ Social Characteristics } \\
\hline age (single year) & 999 & $(0.979-1.02)$ & 0.928 & 1.085 & $(1.060-1.110)$ & $p<0.001$ & 1.047 & $(1.025-1.069)$ & $p<0.001$ \\
\hline male & \multicolumn{2}{|c|}{ reference category } & & \multirow{2}{*}{$\begin{array}{c}- \\
1.164\end{array}$} & \multirow{2}{*}{$\begin{array}{c}- \\
(0.986-1.375)\end{array}$} & \multirow{2}{*}{$\begin{array}{c}- \\
0.073\end{array}$} & \multirow{2}{*}{$\begin{array}{c}- \\
0.952\end{array}$} & \multirow{2}{*}{$\begin{array}{c}- \\
(0.815-1.111)\end{array}$} & \multirow{2}{*}{$\begin{array}{c}- \\
0.530\end{array}$} \\
\hline female & 0.984 & $(0.849-1.141)$ & 0.835 & & & & & & \\
\hline 'White' & \multicolumn{2}{|c|}{ reference category } & & - & - & - & \multirow{3}{*}{$\begin{array}{l}0.953 \\
0.916\end{array}$} & & \multirow{2}{*}{$\begin{array}{c}- \\
0.657\end{array}$} \\
\hline Ethnic group & 1.227 & $(0.993-1.517)$ & 0.058 & 0.855 & $(0.679-1.078)$ & 0.186 & & $(0.770-1.179)$ & \\
\hline 'Asian' & 1.218 & $(0.994-1.491)$ & 0.057 & 0.572 & $(0.445-0.735)$ & $p<0.001$ & & $(0.735-1.142)$ & 0.436 \\
\hline$>£ 50 k$ & \multicolumn{2}{|c|}{ reference category } & & - & - & - & \multirow[b]{2}{*}{1.073} & - & \multirow{2}{*}{-} \\
\hline Household income & 1.126 & $(0.941-1.348)$ & 0.196 & 0.899 & $(0.731-1.107)$ & 0.316 & & $(0.880-1.308)$ & \\
\hline$<£ 15 k$ & 1.053 & (0.838 - & 0.658 & 1.035 & $(0.796-1$ & 0.799 & 1.055 & $(0.825-1$ & 0.669 \\
\hline \# of household residents & 1.034 & $(0.978-1.094)$ & 0.234 & 0.962 & $(0.902-1.025)$ & 0.234 & 0.926 & $(0.871-0.984)$ & 0.014 \\
\hline Acrececto vohiclo & \multicolumn{2}{|c|}{ reference category } & & \multirow{2}{*}{$\begin{array}{c}- \\
1.375\end{array}$} & \multirow{2}{*}{$\begin{array}{c}- \\
(1.095-1.726)\end{array}$} & - & \multirow{2}{*}{$\begin{array}{c}- \\
1.82\end{array}$} & \multirow{2}{*}{$\begin{array}{c}- \\
(1.468-2.256)\end{array}$} & \multirow{2}{*}{$p<0.001$} \\
\hline Access to venicie & 2.334 & $(1.861-2.926)$ & $p<0.001$ & & & 0.006 & & & \\
\hline Environmental Characteristics & & & & & & & & & \\
\hline Inner London & ref & $y$ & & - & - & - & - & - & - \\
\hline Outer London & 0.825 & $(0.657-1.035)$ & 0.096 & 1.118 & $(0.865-1.445)$ & 0.394 & 1.212 & $(0.956-1.536)$ & 0.112 \\
\hline (least deprived) IMD Q1 & refe & ence category & & - & - & - & - & - & - \\
\hline IMD Q2 & 0.958 & $(0.755-1.216)$ & 0.724 & 0.918 & $(0.693-1.216)$ & 0.549 & 0.919 & $(0.716-1.179)$ & 0.506 \\
\hline Area Deprivation & 1.037 & $(0.812-1.325)$ & 0.770 & 1.015 & $(0.771-1.335)$ & 0.918 & 1.000 & $(0.777-1.286)$ & 0.997 \\
\hline IMD Q4 & 0.938 & $(0.728-1.207)$ & 0.618 & 0.785 & $(0.587-1.051)$ & 0.104 & 0.752 & $(0.576-0.981)$ & 0.036 \\
\hline (most deprived) IMD Q5 & 1.007 & $(0.748-1$ & 0.962 & 0.828 & $(0.596-1.150)$ & 0.259 & 0.888 & $(0.657-1.201)$ & 0.441 \\
\hline traffic volume ( 1,000 vehicles) & 0.985 & $(0.967-1.003)$ & 0.100 & 1.014 & $(0.994-1.034)$ & 0.180 & 1.025 & $(1.005-1.046)$ & 0.016 \\
\hline speed (kph) & 1.006 & $(0.985-1.027)$ & 0.565 & 0.999 & $(0.975-1.024)$ & 0.939 & 0.975 & $(0.955-0.996)$ & 0.022 \\
\hline \# of junctions & 0.999 & $(0.996-1.002)$ & 0.528 & 0.993 & $(0.989-0.997)$ & $p<0.001$ & 0.993 & $(0.989-0.997)$ & 0.001 \\
\hline density of A roads & 0.999 & $4-1.004)$ & 0.698 & 1.004 & $(0.998-1.010)$ & 0.150 & 1.001 & $(0.996-1.007)$ & 0.567 \\
\hline density of minor roads & 1.001 & $(0.999-1.002)$ & 0.411 & 1.001 & $(0.999-1.003)$ & 0.346 & 1.001 & $(0.999-1.003)$ & 0.287 \\
\hline Proportion of postcodes characterised as business & 0.998 & $(0.982-1.016)$ & 0.853 & 1.023 & $(1.004-1.042)$ & 0.017 & 1.038 & $(1.018-1.058)$ & $p<0.001$ \\
\hline
\end{tabular}


Table 3: Associations between social and environmental characteristics and walking distances (log transformed) among children who do some walking

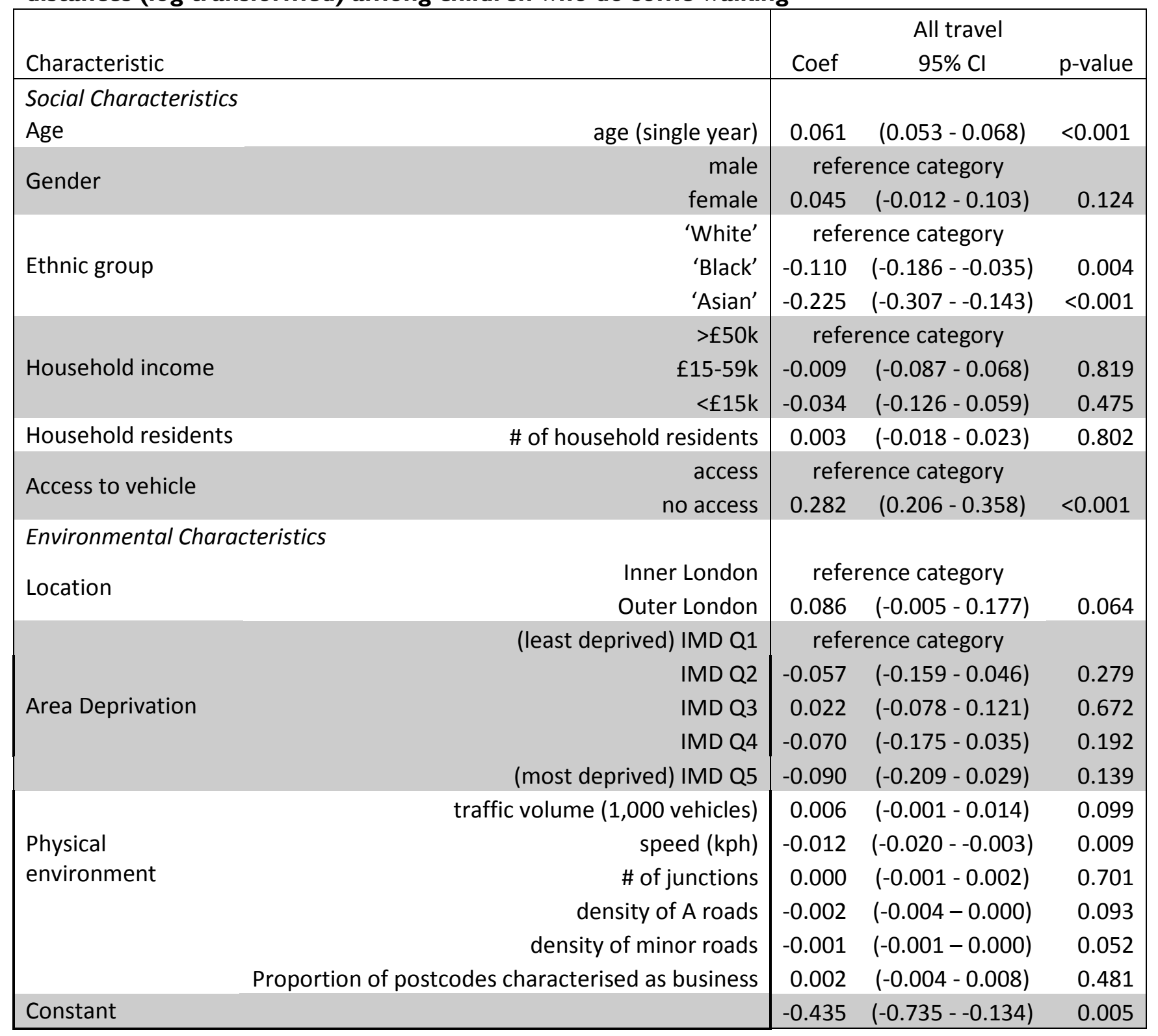


Web Appendix: Mean times (minutes) walked by children by selected social and environmental characteristics

\begin{tabular}{|c|c|c|c|}
\hline Demographic & $\begin{array}{l}\text { Term time weekday } \\
\text { travel to school }\end{array}$ & $\begin{array}{c}\text { Term time weekday } \\
\text { other travel }\end{array}$ & $\begin{array}{c}\text { Summer and } \\
\text { weekend travel }\end{array}$ \\
\hline \multirow{2}{*}{\multicolumn{4}{|c|}{$\begin{array}{l}\text { Social characteristics } \\
\text { Age }\end{array}$}} \\
\hline & & & \\
\hline $5-11$ & $14.16(13.46$ - 14.86) & $4.31(3.55-5.07)$ & $11.78(10.62-12.95)$ \\
\hline $12-17$ & $19.78(18.73-20.84)$ & $6.55(5.84-7.26)$ & $13.81(12.59-15.04)$ \\
\hline \multicolumn{4}{|l|}{ Gender } \\
\hline Male & $16.71(15.86-17.56)$ & $4.96(4.18-5.75)$ & $12.46(11.29-13.62)$ \\
\hline Female & $16.94(16.01-17.87)$ & $5.80(5.10-6.49)$ & $13.08(11.86-14.31)$ \\
\hline \multicolumn{4}{|l|}{ Ethnic group } \\
\hline 'White' & $16.44(15.58-17.30)$ & $6.00(5.23-6.77)$ & $13.79(12.49-15.10)$ \\
\hline 'Black' & $18.65(17.21-20.10)$ & $5.26(4.19-6.33)$ & $11.92(10.47-13.37)$ \\
\hline 'Asian' & $15.90(14.69-17.11)$ & $3.33(2.54-4.13)$ & $9.99(8.60-11.38)$ \\
\hline \multicolumn{4}{|l|}{ Household income } \\
\hline$>£ 50 k$ & $14.29(13.12-15.46)$ & $5.36(4.44-6.29)$ & $12.84(10.94-14.74)$ \\
\hline$f 15-50$ & $16.80(15.81$ - 17.78$)$ & $4.54(3.97-5.11)$ & $12.32(11.13-13.52)$ \\
\hline$<£ 15 k$ & $18.55(17.44-19.65)$ & $6.46(5.24-7.68)$ & $13.33(11.84-14.82)$ \\
\hline \multicolumn{4}{|l|}{ Vehicle access } \\
\hline Access & $15.14(14.43-15.85)$ & $4.59(4.12-5.06)$ & $11.43(10.49-12.37)$ \\
\hline No access & $21.02(19.75-22.28)$ & $7.31(5.91-8.72)$ & $16.20(14.45-17.96)$ \\
\hline \multirow{2}{*}{\multicolumn{4}{|c|}{$\begin{array}{l}\text { Environmental characteristics } \\
\text { Location }\end{array}$}} \\
\hline & & & \\
\hline Inner London & $17.20(16.14-18.26)$ & $5.44(4.70-6.17)$ & $14.16(12.59-15.72)$ \\
\hline Outer London & $16.61(15.83-17.39)$ & $5.33(4.63-6.04)$ & $11.98(11.00-12.96)$ \\
\hline \multicolumn{4}{|l|}{ Area Deprivation } \\
\hline (least deprived) Q1 & $15.51(14.12-16.90)$ & $5.06(3.96-6.17)$ & $12.66(10.82-14.51)$ \\
\hline Q2 & $16.13(14.69-17.57)$ & $5.03(4.08-5.98)$ & $11.90(10.06-13.74)$ \\
\hline Q3 & $17.60(16.00-19.21)$ & $6.21(4.56-7.87)$ & $14.86(12.44-17.27)$ \\
\hline Q4 & $16.38(15.02-17.73)$ & $4.94(4.02-5.85)$ & $11.57(10.06-13.08)$ \\
\hline (most deprived) Q5 & $18.01(16.79-19.24)$ & $5.47(4.48-6.46)$ & $12.85(11.14-14.56)$ \\
\hline \multicolumn{4}{|l|}{ Mean traffic volumes } \\
\hline (least traffic) T1 & $16.36(15.38-17.33)$ & $3.92(3.34-4.50)$ & $10.62(9.27-11.97)$ \\
\hline $\mathrm{T} 2$ & $17.23(16.19$ - 18.27) & $5.38(4.65-6.12)$ & $13.73(12.18$ - 15.27) \\
\hline (most traffic) T3 & $16.90(15.62-18.17)$ & $7.00(5.67-8.34)$ & $14.03(12.59-15.47)$ \\
\hline \multicolumn{4}{|l|}{ Traffic speeds } \\
\hline$<25 \mathrm{kph}$ & $16.72(15.36-18.08)$ & $5.11(4.17-6.04)$ & $14.50(12.77-16.23)$ \\
\hline $25-35 \mathrm{kph}$ & $17.02(16.24-17.80)$ & $5.55(4.86-6.23)$ & $12.47(11.41-13.53)$ \\
\hline$>35 \mathrm{kph}$ & $15.93(14.22-17.64)$ & $4.86(3.49-6.23)$ & $11.27(9.09-13.44)$ \\
\hline
\end{tabular}


Web Appendix: Associations between social and environmental characteristics and walking times (log transformed) among children who do some walking

\begin{tabular}{|c|c|c|c|}
\hline \multirow[b]{2}{*}{ Characteristic } & \multicolumn{3}{|c|}{ All travel } \\
\hline & Coef & $95 \% \mathrm{Cl}$ & $p$-value \\
\hline \multicolumn{4}{|l|}{ Social Characteristics } \\
\hline age (single year) & 0.030 & $(0.023-0.036)$ & $<0.001$ \\
\hline male & \multicolumn{3}{|c|}{ reference category } \\
\hline female & 0.054 & $(0.003-0.105)$ & 0.037 \\
\hline 'White' & \multicolumn{2}{|c|}{ reference category } & \\
\hline Ethnic group & -0.104 & $(-0.172--0.037)$ & 0.003 \\
\hline 'Asian' & -0.170 & $(-0.238--0.102)$ & 0.000 \\
\hline \multirow{3}{*}{ Household income } & \multicolumn{2}{|c|}{ reference category } & \\
\hline & 0.002 & $(-0.066-0.070)$ & 0.955 \\
\hline & -0.018 & $(-0.100-0.063)$ & 0.659 \\
\hline \# of household residents & -0.003 & $(-0.021-0.015)$ & 0.739 \\
\hline Access to vehicle & \multicolumn{2}{|c|}{ reference category } & \\
\hline no access & 0.217 & $(0.148-0.286)$ & $<0.001$ \\
\hline Environmental Characteristics & \multirow{2}{*}{\multicolumn{2}{|c|}{ reference category }} & \\
\hline Inner London & & & \\
\hline Outer London & 0.036 & $(-0.041-0.113)$ & 0.359 \\
\hline (least deprived) IMD Q1 & \multicolumn{2}{|c|}{ reference category } & \\
\hline IMD Q2 & -0.018 & $(-0.109-0.074)$ & 0.708 \\
\hline Area Deprivation & 0.069 & $(-0.023-0.161)$ & 0.140 \\
\hline IMD Q4 & -0.026 & $(-0.120-0.068)$ & 0.584 \\
\hline (most deprived) IMD Q5 & 0.041 & $(-0.064-0.146)$ & 0.448 \\
\hline \multirow{7}{*}{$\begin{array}{r}\text { traffic volume }(1,000 \text { vehicles }) \\
\text { speed }(\mathrm{kph}) \\
\text { \# of junctions } \\
\text { density of A roads } \\
\text { density of minor roads }\end{array}$} & 0.006 & $(0.000-0.013)$ & 0.057 \\
\hline & -0.006 & $(-0.014-0.001)$ & 0.090 \\
\hline & 0.001 & $(-0.001-0.002)$ & 0.375 \\
\hline & -0.001 & $(-0.003-0.000)$ & 0.135 \\
\hline & 0.000 & $(-0.001-0.000)$ & 0.358 \\
\hline & 0.000 & $(-0.005-0.006)$ & 0.882 \\
\hline & 2.773 & $(2.508-3.039)$ & $<0.001$ \\
\hline
\end{tabular}


Web Appendix: associations between social and environmental characteristics and walking all the way to school




